\title{
Assessment of the Method of Merging Landing Aircraft Streams in the Context of Fuel Consumption in the Airspace
}

\author{
Anna Kwasiborska *(D) and Jacek Skorupski \\ Faculty of Transport, Warsaw University of Technology, Koszykowa 75, 00-662 Warsaw, Poland; \\ jacek.skorupski@pw.edu.pl \\ * Correspondence: anna.kwasiborska@pw.edu.pl
}

check for

updates

Citation: Kwasiborska, A.; Skorupski, J. Assessment of the Method of Merging Landing Aircraft Streams in the Context of Fuel Consumption in the Airspace. Sustainability 2021, 13, 12859. https://doi.org/10.3390 /su132212859

Academic Editors: Hartmut Fricke and Judith Rosenow

Received: 14 October 2021

Accepted: 17 November 2021

Published: 20 November 2021

Publisher's Note: MDPI stays neutral with regard to jurisdictional claims in published maps and institutional affiliations.

Copyright: (C) 2021 by the authors. Licensee MDPI, Basel, Switzerland. This article is an open access article distributed under the terms and conditions of the Creative Commons Attribution (CC BY) license (https:/ / creativecommons.org/licenses/by/ $4.0 /)$.

\begin{abstract}
The most important directions in the field of sustainable development of air transport concern increasing the capacity of airports and improving the global civil aviation system, improving air traffic safety, and developing procedures to optimize the operation of the aviation system. An important area is environmental protection and measures to minimize the negative impact of civil aviation activities on the environment. Air traffic and the operation of airports generate adverse environmental effects, including greenhouse gas emissions, air pollution, and noise emissions. Due to the high intensity of aircraft maneuvers, the authors analyzed aircraft traffic in the area approaching the airport. It is essential to correctly line up for aircraft reporting from different entry points to the approach area to avoid waiting for landing. Misalignment of landing aircraft negatively impacts airport capacity, increases fuel consumption through more prolonged waiting times in space, and directly impacts air pollution. There are different ways to organize landing aircraft flows and other ways to merge these flows. The article aims to assess the method of combining the streams of landing aircraft and estimate the impact of such an organization on the increased fuel consumption of aircraft and thus on air pollution. The authors proposed a measure for assessing the quality of the landing queue, which was defined as the increase in flight time of aircraft in the approach area in relation to the nominal time, which was adopted as minimization. In order to obtain the results of research works, a model using a Petri net was developed, allowing for flexible mapping of concurrent processes and their effect analysis. Various methods of combining the streams of landing aircraft have been adopted: three-stage, two-stage, and single-stage. Then, simulation experiments were carried out, allowing the determination of whether the method of combining the streams of landing planes has an impact on the quality of the landing queue measured with the proposed index. The obtained results of the assessment can be used to estimate the increased fuel consumption of the aircraft.
\end{abstract}

Keywords: air pollution; environmental protection; safety; landing aircraft scheduling; Petri nets; merging points; traffic flow management

\section{Introduction}

Air traffic is subject to the processes of monitoring and controlling its flow. The aim of management is not only to direct traffic control but also to plan and coordinate its adequate flow to optimize the use of available airspace. Air traffic is subject to various legal, environmental, and technical regulations, and the overriding goal is to ensure the required level of safety of the performed air operations. Terminal control areas are sensitive areas of the airspace where arrival and departure traffic take place. Critical airspace areas with high traffic intensity require specific analysis. These areas undoubtedly include the Terminal Control Area, TMA, where streams of landing aircraft from different directions merge. Improving traffic organization in this area may result in the minimization of delays or better use of runways. One of the tasks of the APP approach control services, responsible for air traffic control in the TMA area, is the scheduling of landing aircraft. The task of air traffic control is to ensure safe horizontal and vertical separations between aircraft in a 
controlled space. The values of the separations used in controlled airports with an influx of landing streams from many directions are becoming critical. One should also consider the possibility of disturbances and the need to change the decisions already made by the inspector. This may involve a complete change of the assumed configuration of planes in the approach zone or even in the queue for landing. Such extreme conditions make it necessary to make quick decisions while maintaining the level of safety and at the same time paying attention to operational values.

The most important goal is safety in air traffic, which is supervised by the air traffic control unit. To this end, the air traffic control service receives information on the intended movements of each aircraft and current information on the progress of the flight. Based on the information received, the controller should determine the positions of known aircraft concerning itself. To prevent aircraft collisions, permits are issued to ensure the safety and orderly flow of air traffic. It is essential to coordinate permits with other air traffic units. Any wrong decision made by air traffic controllers will result in a dangerous situation. Therefore, tools to support the work of people responsible for air traffic control, mainly in the controlled area of the TMA airport, are constantly being sought. The main concern of APP controllers is deciding which aircraft should land first. If the airport has a single runway, it is essential to arrange the approaching aircraft correctly, with minimal distance and time separation.

On the other hand, if an airport has several runways, it is important to assign the runway in use to a specific aircraft. In a situation of increasing traffic, it is necessary to look for possible ways to optimize the flow of air traffic. Placing in the right queue at an earlier time horizon can bring tangible benefits. The AMAN (arrival manager) system was developed to increase runway capacity by sequencing landing aircraft. AMAN allows to increase the precision of the approach trajectory and supports the sequencing of air traffic at an earlier stage (from 100-120 to 180-200 NM from the place where the aircraft starts descending) [1].

From the point of view of air traffic control in TMA, the standard STAR/SID procedures, which are based on RNAV area navigation and determined following IFR regulations, play an essential role. The purpose of introducing these procedures was to improve and ensure greater efficiency and safety of air traffic in the TMA regions. Aircraft movement follows specific trajectories, and the possible collision of the trajectories used is minimized at designing procedures. Therefore, it becomes evident that their use helps reduce the workload of the ATC traffic controller and allows the improvement of STAR/SID procedures to be associated with increasing airport capacity. According to the published STAR arrival standard maps, air traffic flows are routed along designated routes, connecting with each other at common waypoints. Streams are intensified while maintaining proper separations.

Nevertheless, under certain conditions (especially outside peak traffic hours), performing the procedure along the full route seems to be a highly ineffective solution. For this reason, it is recommended that traffic control authorities use shortcuts through the use of RNAV points. Identification and analysis of landing aircraft streams, structure, intensity, and organization methods can provide several important data for verifying activities related to optimizing air traffic flow. Proper aircraft scheduling during an approach to landing may increase the number of operations performed during a time unit and minimize fuel consumption. Allocation of times to given aircraft is related to ensuring adequate airport capacity and punctuality of air operations. Inadequate timing of the operations will result in the lack of smoothness of traffic and, consequently, the occurrence of the problem of congestion.

In air traffic, safety is the most important constraint considered during its organization and control. It is achieved by maintaining appropriate separations between aircraft. In the case of landing sequence optimization, separations are variable in different stages of traffic and depend, among other things, on the size of the aircraft. We took this problem into account; in each of the strategies of combining streams, the model considers the separation behavior at each stage of the process. We used vectoring because it is the most commonly 
used of the several possible ways to ensure separation. In addition, it is directly related to the time of landing sequences.

In the literature, other criteria and limitations are used in landing sequence optimization, for example, the number of delayed arrivals or the maximum time of the delayed flight. The latter aspect is also essential in terms of safety, as it may be associated with too low a fuel level. Criteria such as reduction of air traffic controller workload or maintaining equity among airlines may also be considered.

\subsection{Literature Review}

In air traffic, scheduling theory is becoming increasingly important for improving air traffic organization. The history of scheduling theory begins at the beginning of the last century with the Industrial Revolution. This problem is perceived as essential and discussed in official regulations as well as in scientific publications. The problem that air traffic controllers also face is the time frame in which aircraft should land. This is related to the issue of allocating to aircraft by airports time to perform an operation (take-off, landing). The issue of the sequencing of landing aircraft can be analyzed with the use of the theory of task scheduling in machine systems operating in parallel [2]. This problem was compared with the issues of sequencing the work of $\mathrm{n}$ tasks (take-offs and landings) on one machine (runway). A division and estimation algorithm was developed, in which modifications were made using certain specific properties identified in air traffic. According to the authors, the proposed approach could be used to study more complex problems, with more runways and considering several classes of aircraft. The literature describes proper landing scheduling (e.g., [3,4]) and taking off aircraft. For example, in [4], models and algorithms are presented, intended for control in the TMA region. The authors [5] suggested an exciting method of assessing the landing aircraft scheduling process based on determining the number of landings possible for a given ranking per time unit. The issue of sequencing of landing aircraft streams using task scheduling methods has been discussed in $[1,6]$. Among the papers on air traffic, but not using formal scheduling algorithms, one can mention, for example, [1]. It presents a model to evaluate traffic control strategy in the TMA region. This model includes several inlet points to the region and several routes to selected landing approach endpoints. The paper presents the implementation of the model to support air traffic management in the area of the Rome-Fiumicino airport. The authors point to the universality of the model and the possibility of applying solutions at other airports.

A similar issue in more contemporary realities is considered in [7]. An approach to the problem of landing sequencing is presented in [8]. The article proposes an algorithm whose key role is to reconcile the landing time with the airline's preferences. The issue of the correct (desired) landing time is discussed in [9]. It considers the attainability of the required time of arrival (RTA) and, basically, the controlled time of arrival (CTA) derived from it. This important issue shows that determining the time of arrival at a measurement point known as required time of arrival (RTA) can provide the basis for sequencing aircraft for landing. Unfortunately, the use of RTA is not a complete solution but is only a helpful tool in air traffic management.

The scientific area for scheduling landing aircraft may be airport-specific or, where the problem is theoretically addressed, multiple runways [10,11]. In addition to determining the appropriate sequence of landing aircraft, it is also important to develop aircraft locations to maximize the desired effect while maintaining a proper level of safety [12]. Moreover, the adequate creation of an optimal aircraft sequence affects airport capacity and is related to delays [13]. The simple method of scheduling and planning landing aircraft on one runway usually uses the FCFS method; however, it has been noticed that this method rarely provides the best landing queue solution, taking into account airport capacity or average delay [14].

The work [15] focuses on presenting the concept of implementation of a system for assessing the landing aircraft scheduling process. The evaluation method is based on 
determining the number of landings that can be made with a given ranking per unit of time. It has been shown that landing aircraft can be arranged to achieve a much smaller number of landings per time unit than the regulations require. The authors indicate that there is great potential in the implementation of controller support systems in the landing aircraft scheduling process.

It should be pointed out that the application of scheduling methods or the construction of new models aimed at sequencing aircraft are particularly important.

A new method of scheduling aircraft based on point merge is a concept that was developed by the EUROCONTROL Experimental Center in 2006. It combines incoming aircraft flows (pre-sequencing at the ACC Area Control Center) into a single TMA entry point that uses the aircraft's precise area navigation (P-RNAV).

The Point Merge System concept in high-density sectors and complex TMA (extended TMA) areas replaces radar vectoring with a more efficient and simplified traffic synchronization mechanism that reduces the traffic load and increases the sequencing of collective traffic to TMA. This enables inbound traffic to be efficiently sequenced while supporting continuous lowering operations.

The authors [16] described the sequencing of landing aircraft, taking into account the minimization of the schedule length. They applied selected theoretical algorithms, then they were verified, and a methodology for determining the sequence of landing operations was developed, ensuring the shortest possible execution of all operations. However, the authors point out that there are no universal sequencing methods, and there is a need for research in this field. The authors [17] presented the problem of optimizing the use of the runway in conditions of uncertainty, focusing on the pre-tactical planning phase. The developed mathematical model allowed determining the number of planes in a given time window. Among other works in which the problem of runway scheduling was investigated with uncertainty, stochastic programming was used [18].

\subsection{Air Traffic Organization in TMA}

TMAs play a critical role in the airspace structure due to aircraft maneuvering involved in approach, landing, take-off, and climb operations. In the vicinity of the airport, there is an apparent intensification and congestion of traffic flows. There are two types of landing and taking-off traffic flows. The elements of air traffic organization in the TMA area are arrival and approach procedures and departure procedures. These are relevant formal provisions aimed at simplifying traffic management and thus ensuring a high level of safety during flight operations at the end of the flight. The procedures consist of imposing altitude and airspeed limitations on the aircraft and are described by the terrain around the airport, the type of flight operation performed, and the type of aircraft. A standard arrival route (STAR) is a designated instrument flight route (IFR) that governs aircraft movement by giving specified routes, speeds and altitudes. Speed control is an essential element in correcting separation between aircraft. The general speed limitation procedure for landing aircraft takes into account the requirements specified in Doc 4444. The safety of air operations in space is achieved by providing radar separation based on radar imaging of the traffic situation. The minimum radar separation is $5 \mathrm{NM}$, while its reduction to $3 \mathrm{NM}$ is allowed for aircraft positioned within $16 \mathrm{NM}$ from the radar antenna.

Introducing these procedures aims to improve and ensure greater efficiency and safety of air traffic in the TMA area. For aircraft performing these procedures, the course of operations takes place along predetermined trajectories, and the possible collision of the trajectories used is minimized at the stage of designing the procedures. The use of procedures helps reduce the workload of the ATC traffic controller and allows increasing the airport capacity. Inspectors often use arrival itineraries bypassing certain points in the STAR procedure by arranging to fly directly between any two waypoints. The controller then gives a shortcut or specifies a direct route. This action is common because it allows aircraft to reduce the time it takes to complete a landing operation and reduce fuel consumption. It is also an essential tool for changing the natural arrival sequence. Providing a shortcut by 
reducing the distance to travel allows "overtaking" another aircraft, and thus changes the landing sequence. At individual waypoints, the STAR procedures define standard aircraft speeds. They were included in the created model and computer tool for determining the time of flight between points and verification of the separation. In traffic around the airport, as in other parts of the airspace, to ensure safety, time or distance separations are used between successive aircraft approaching landing. In order to maintain air traffic safety and to maintain the recommended air capacity, the following techniques are also used:

- delaying approaches landing and departure;

- $\quad$ reducing speed during the flight path to minimize delay;

- $\quad$ sequencing of successive approaches to maximize aircraft or minimize delays;

- $\quad$ reducing the runway occupancy time by effectively adjusting the arrival speed of landing aircraft.

\subsection{The Concept of Research Work}

Research work on the analysis of landing aircraft traffic at TMA focused mainly on determining the correct sequence of landings taking into account various target functions and constraints. The authors of many studies assume that obtaining these sequences is technically possible, but it may be a problem in practice. The occurrence of delays usually causes changes in the originally planned configuration of the aircraft, changing the method of merging flows and the number of such mergers.

In areas of high traffic, shortcuts are not always possible and justified from the point of view of traffic safety in this area, despite the potential economic benefits. The success of sequencing algorithms largely depends on how the operation is actually performed. This paper is a continuation of the previous research by the authors $[19,20]$ in the area of the problem of scheduling the streams of landing aircraft. These articles mainly analyzed the use of shortcuts, i.e., changes to the standard flight route, which are the primary technical means to achieve the planned sequence. On the other hand, the article [21] uses the modeling of aircraft traffic in TMA using colored Petri nets to analyze scheduling effectiveness under disturbance conditions. In the current article, the authors extend previous research.

The influence of the selection of aircraft stream merge points on the quality of the queue was analyzed. A model was built in the CPN Tools 4.0 environment based on colored, hierarchical, and priority Petri nets and implemented for the sample Chopin Airport. The quality of the landing queue was assessed by the total time of completing the aircraft sequence. When assessing the implementation of individual scenarios, it was taken into account to minimize the increase in the execution time of the aircraft sequence compared to the nominal sequence execution time. The simulations performed allowed answering the research question of whether it is better to determine the trajectory after abbreviations for all aircraft, i.e., one level of merge or two different connection points, or whether the aircraft trajectories should be carried out according to the developed procedure. The scheduling process investigated how the selection of connection points affects the quality of the queue. For the comparability of the results of all simulations, they were carried out for the same plan of arrivals, i.e., times and points of the aircraft reporting to the approach area.

Figure 1 presents a general scheme of merging aircraft arrival to the TMA and developing various possibilities of forming streams of landing aircraft. The object of scheduling landing airplanes is the set of $A=\{A 1, \ldots, A i\}$, aircraft arriving on a given runway within a specified interval. The general concept of modeling the air traffic process in the airport area consists of mapping sections of airways and navigation points in a graph. 


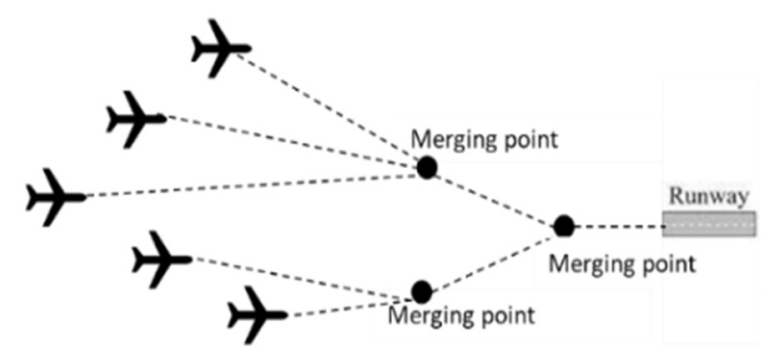

Figure 1. General scheme of merging the streams of landing aircraft.

Let the graph $G$ be a graph with $n$ vertices $\left(w p_{1}, w p_{2}, \ldots, w p_{\mathrm{n}}\right)$ and $m$ edges $\left(e_{1}, e_{2}, \ldots\right.$ $\left.e_{\mathrm{m}}\right)$. Matrix $A(G)=\left[a_{\mathrm{ij}}\right] n \times m$ for $i=1, \ldots n, j=1, \ldots, m$ is defined as follows:

$$
a_{\mathrm{ij}}=\left\{\begin{array}{c}
1 \text { edge } e_{\mathrm{j}} \text { is incidental to i vertice } w p_{\mathrm{i}} \\
0 \text { otherwise }
\end{array}\right.
$$

Air routes are described in the form of a graph. The graph edge weights reflect the distances between the individual navigation points. Figure 2 shows the standard form of the graph reflecting the possible trajectories of the aircraft according to the established procedure, without realizing shortcuts.

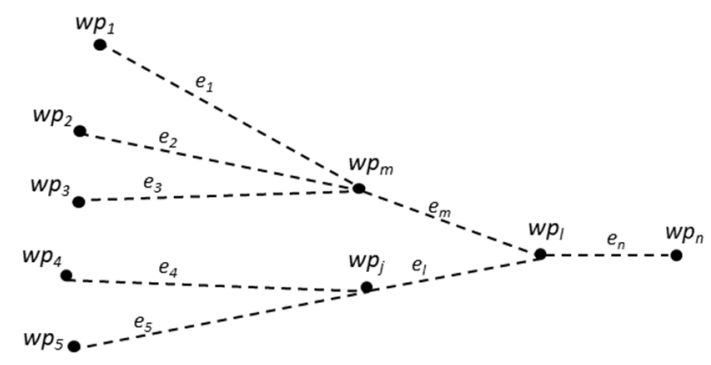

Figure 2. Sample STAR procedure graph.

Arrival aircraft to TMA at the vertices $\left(w p_{1}, w p_{2}, \ldots, w p_{\mathrm{n}}\right)$ represent waypoints. At each of these peaks, standard aircraft speeds are defined for which nominal times of stay in the approach area were calculated. The edges of the graph are defined by the distances between the navigation points $\left(x_{1}, x_{2}, \ldots, x_{\mathrm{n}}\right)$ and are given in NM (Table 1$)$.

Table 1. Marks of the route length in the STAR procedure.

\begin{tabular}{cccccc}
\hline Procedure & $w p_{1}$ & $w p_{2}$ & $w p_{3}$ & $w p_{4}$ & $w p_{\mathrm{n}}$ \\
\hline Length $(\mathrm{NM})$ & $x_{1}$ & $x_{2}$ & $x_{3}$ & $x_{4}$ & $x_{\mathrm{n}}$ \\
\hline
\end{tabular}

Aircraft are operating under the STAR procedure report at the TMA entry points until the final straight approach. It is possible to set the aircraft differently than it is mandated by the STAR procedure; namely, different routes in the graph will indicate another connection point for the aircraft. Such an implementation reduces the number of merging points for aircraft streams and thus may have an impact on a different positioning of aircraft for landing. The authors analyzed various scenarios of route selection by using various merging points of landing aircraft streams.

The work [21] aimed to create a method for assessing the sequence of landing aircraft during random disturbances. In the current article, we have dealt more with a decision strategy to obtain the resulting sequence. There are numerous time losses in this process due to the need to merge the streams at selected waypoints securely. Therefore, the resulting landing sequence is not assessed, but the time losses (and indirectly consumed fuel) during its formation are. Additionally, we are dealing here with a much longer horizon of analysis. We proposed a measure of the quality of the landing queue formation process, defined 
as the increase in aircraft flight time in the terminal area compared to the nominal time. Thanks to the adopted approach, it was possible to evaluate the algorithms for combining streams of landing aircraft and indicate the relationship between their selection and fuel consumption, and thus air pollution, during the flight through the TMA region. It was also stated that creating a queue of landing aircraft has an impact on the economic aspect.

\section{Air Traffic Model in TMA}

\subsection{General Assumptions of the Model}

Modeling a complex and dynamic system of aircraft movement in the approach area forces the search for methods that enable flexible mapping of the structure and its dependencies. Petri nets are a convenient and effective tool for modeling transport processes based on the theory of graphs and networks. The paper adopts the following assumptions:

1. An aircraft landing stream is a collection of airplanes intended to approach a landing on a given runway.

2. The process of combining several aircraft streams starting at the TMA entry points and ending with a landing on the same runway shall be analyzed.

3. Each STAR procedure navigation point can be a shortcut start and endpoint.

4. A trajectory described by waypoints and the time $t_{\mathrm{i}}$ arrival at these waypoints has been determined for each arrival aircraft to the TMA.

5. The landing queue is set up on the FCFS basis according to the order of reporting. It can be changed by defining non-standard merging points.

6. The aircraft flight plan is generated based on the assumed spacing between the aircraft's arrival to the entrance gate of the TMA area. Five variants of the appearance of aircraft on individual inlet gates have been developed. Time intervals between aircraft were assumed to be 60,70,80, and $90 \mathrm{~s}$. and random entries.

7. During traffic planning, the difference between appearance times over a waypoint of two aircraft may be less than the minimum separation $\left(t_{\mathrm{i}+1}-t_{\mathrm{i}}\right)<t_{\mathrm{sep}}$. Considering the average speed $v_{i}$ of a given aircraft in this flight phase and the typically used radar separations, it was assumed that the minimum $t_{\text {sep }}$ separation at the inlet gates was $64 \mathrm{~s}$. Separations between aligned airplanes shall not be less than $90 \mathrm{~s}$.

8. Separation will be maintained by specifying a minimum time of succession. If it requires adjusting the time it takes for the aircraft to appear above the point by $60 \mathrm{~s}$ or less, it will be done by adjusting the speed of the next applicant. Correction for a time from 60 to $120 \mathrm{~s}$ shall be made by vectoring or changing the speed $v_{i+1}$ of the later arriving aircraft. If maintaining the separation requires a correction by more than $120 \mathrm{~s}$, then the moment of reporting the aircraft at the TMA entrance gate is modified, i.e., all maneuvers adjusting the reporting time are performed at an earlier stage of the flight.

9. An air traffic controller has two types of decision variables at its disposal. The first is to determine the number of stream blending levels (the actual route with shortcuts). The second variable is the time margin added to the minimum separation to facilitate new planes to the queue and compensate for the negative impact of interference.

\subsection{Petri Nets as Applied to Air Traffic Modeling}

The Petri net was used to model air traffic in the TMA, which is constructed as a directed bipartite graph. The CPN Tools 4.0 tool was used to create, simulate, and analyze colored Petri nets. The advantage of using Petri nets is a relatively wide range of tools for computer implementation of models with their application. The elements of the Petri network, presented as a graph, are places, arcs, and transitions with systematized graphical notation along with appropriate inscriptions describing a given element and defining its operation. Modeling of systems using Petri nets is based on designing the network by taking into account both the formality of the mathematical tool and the interpretation of the modeling goal. 
In the literature, there are articles that describe the application of this area. The authors [22] presented a time model of a stochastic Petri net for a single runway by analyzing the impact of taxiway availability on the runway capacity. The method can be used to plan optimal sequences on a small scale. Movement processes in transport take place in a specific space, taking into account their implementation at a specific time; therefore, the occurring sequences of events require the determination of time dependencies. The use of time networks enables the implementation of such models, and the extension of the modeling scope by random events is possible with the use of stochastic networks. Aircraft streams are rarely uniform with respect to different technical specifications, performance, and weight classes. Petri nets were also used to analyze aircraft take-off operations [23], the proper functioning of which affects the airport capacity. The authors [24] used Petri nets to model aircraft taxi routes in the Advanced Surface Traffic Navigation and Control System (A-SMGCS), indicating that the planned dynamic route may reduce potential conflicts and shorten aircraft waiting times, increasing airport capacity. The paper [25] presents a model of the aircraft turning process on the tarmac illustrated in the examples from Belgrade airport. The process should run smoothly, avoiding losses and additional costs for air carriers. The authors built a model by examining resource allocation strategies (equipment, personnel, etc.) using Petri nets that can be incorporated into an airport operating model.

The purpose of modeling air traffic in the analyzed area is to assess the landing aircraft flows, taking into account the different connection points of the reporting aircraft. The authors adopted the criterion for assessing the quality of the queue as a minimization of the increase in the time spent in the analyzed area to the nominal flight time in the approach area in the adopted scenarios. In most scientific works, the criterion of the air capacity assessed as the basic parameter of the navigational assessment of an airport is adopted. This assumption is, of course, correct, but the movement of the starting SP should also be analyzed. For the purposes of the analysis, only landing aircraft traffic was taken into account.

\subsection{Model Notation in the Form of a Petri Net}

Petri nets [26] are a practical mathematical apparatus, the graphical notation of which and the availability of computer tools facilitate its use for air traffic modeling. Hierarchical colored Petri nets with the following structure were used for research and simulations [27].

$$
S_{\mathrm{AM}}=\left\{P, T, A, M_{0}, \Gamma, C, G, E, B\right\} \mathrm{a}=1,
$$

where:

$P \quad$ - set of places,

$T \quad$-set of transitions $T \cap P=\varnothing$,

$A \subseteq(T \times P) \cup(P \times T)$ - set of arcs,

$M_{0}: P \rightarrow \mathbb{Z}_{+} \times R$ - the initial state of modeled system,

$\Gamma \quad$-finite set of colors corresponding of tokens,

C - function determining of tokens: $C: P \rightarrow \Gamma$,

$G$-function determined the conditions for a given event to occur,

$E$-function describing weights of arcs,

$B \quad: T \rightarrow \mathbb{R}_{+}-$a function describing the priority of a given event.

For the modeling objective formulated in this way, a model implementation in the form of colored, hierarchical, and priority Petri nets was selected. The network hierarchy is implemented by a page mechanism that allows extracting a part of the model. The mechanism of "connected places" in this case implements the synchronization of the pages. Figure 3 relates to the Sort ML model, which is responsible for sorting a list consisting of a sequence of aircraft by time. 


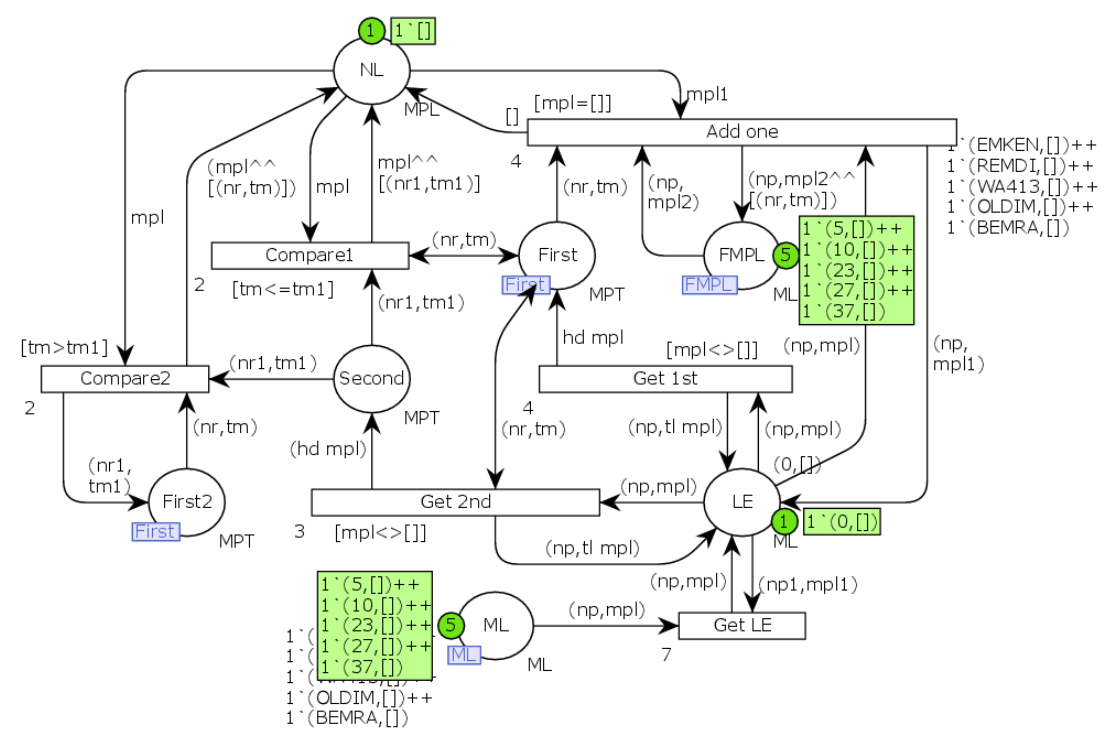

Figure 3. Model Sort ML.

The selected elements of the model are:

Init—carries out initialization procedures and also includes final results.

MkSep-responsible for checking whether all separations are met with the planned sequence; in the case of a negative answer, the distance missing to maintain the separation is determined.

Adjst AC-performs a sequence change by shifting the planned times of appearance over successive waypoints in such a way as to complete the distance missing to maintain separation.

The "selection sort" algorithm is responsible for sorting the sequence list. ML site implements unordered input list storage for sorting. Get 1st takes the first item in the list and puts it first. Then, the Get 2 nd transition is activated, which takes the second item from the list and places it in second place.

Then, the time value of reaching the waypoint contained in both elements of the list is compared. Depending on the result of the comparison, one of the Compare1 or Compare2 transitions is activated. After reviewing the list, NL is replaced by the element with the smallest time value, which should become the first element of the list. The location of the LE contains the ordered list items.

\section{Implementation of the Model at Chopin Airport}

\subsection{Structure of TMA Warsaw}

The TMA region consists of six entry points to this approach region and is represented by a network of interconnecting air routes. Standard STAR procedures (Figure 4) are based on precise RNAV 1 (P-RNA) area navigation and have been defined for each runway at Chopin Airport.

RNAV STAR arrival procedures include segments for a given runway in use and end in FAF/FAP. The selection of these points depends on the traffic situation and the controller's decision and may lead to a shortening of the route already in the initial approach, as well as to a reduction of the indirect approach on a straight approach (extension of the runway axis). It is worth mentioning that the regulations impose the obligation to conduct the inbound traffic in such a way that the landing straight does not exceed 25 NM to the runway threshold (for RWY 11 not further than point WA414). The model uses the point WA413 as the starting point of the straight approach to landing (i.e., $20 \mathrm{NM}$ to the runway threshold). In the analyzed area of TMA Warszawa, the minimum radar separation is 5 NM. A minimum 3 NM radar separation may be used for aircraft within less than 16 NM from the antenna. TMA Warszawa includes six entrance gates: AGAVA, BIMPA, LIMVI, LOGDA, NEPOX, and SORIX. 


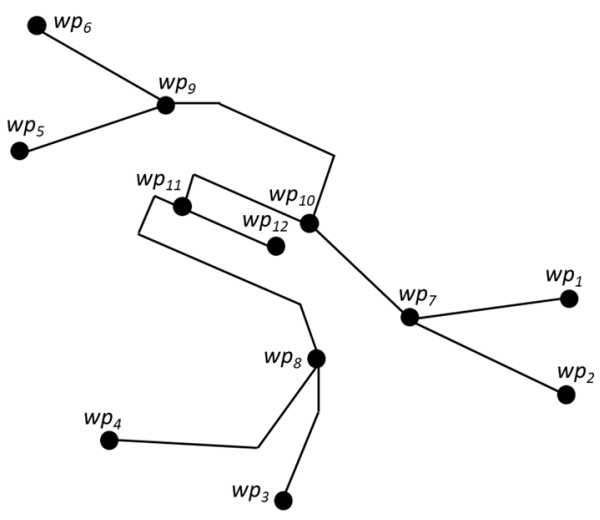

Figure 4. Scheme of STAR-runway RWY11.

The developed hierarchical model reflects the organization of traffic in TMA Warsaw. In the approach area to Chopin Airport in Warsaw, standard STAR arrival procedures have been defined, which facilitate the navigation of the aircraft up to the point where the final approach procedure begins. The flight parameters to be met by an aircraft when passing a waypoint included in the STAR procedure will facilitate a safe approach to landing. Standard STAR procedures at TMA Warszawa are based on P-RNAV precise area navigation. When analyzing the STAR procedure for RWY11, 12 important route points can be distinguished, which are the entry points of the TMA. We denote

$$
W P=\left\{w p_{\mathrm{i}}\right\}, i=1,2, \ldots, w
$$

the set of important waypoints, $w=12$.

The set of entry points we define as

$$
E P=\left\{w p_{\mathrm{i}}\right\}, i=1, \ldots 6
$$

where $w p_{1}=\mathrm{NEPOX}, w p_{2}=\mathrm{LIMVI}, w p_{3}=\mathrm{LOGDA}, w p_{4}=\mathrm{AGAVA}, w p_{5}=\mathrm{BIMPA}$, and $w p_{6}=$ SORIX.

The set of merging points is defined as

$$
M P=\left\{w p_{\mathrm{i}}\right\}, i=7, \ldots 11
$$

where $w p_{7}=\mathrm{EMKEN}, w p_{8}=\mathrm{BEMRA}, w p_{9}=\mathrm{OLDIM}, w p_{10}=\mathrm{REMDI}$, and $w p_{11}=\mathrm{WA} 413$.

The set of scheduling endpoints is denoted

$$
L P=\left\{w p_{\mathrm{i}}\right\}, i=12
$$

where $w p_{12}=$ FAP $/$ FAF.

\subsection{Simulation Experiments}

The following three scenarios were adopted:

(1) 3L-aircraft flight after the full STAR procedure,

(2) 2L-two-step merging of landing planes streams, i.e., flight after the STAR procedure and partly with the use of abbreviations,

(3) 1L-single-step merging of landing aircraft streams, i.e., the use of full shortcuts meaning directing the aircraft from the entrance to the TMA to the navigation point where the landing begins.

The arrival sequence consisted of ten aircraft entering the entry points. The arrival of aircraft were generated every 60, 70, 80, and $90 \mathrm{~s}$ and at random (Table 2). The simulation consisted of one hundred arrival sequences (labeled in order FL, e.g., FL \# 1, FL \# 2, etc.) 
in each of the 10 aircraft. Arrival plans were generated considering the separation at the entrance gates.

Table 2. Example of entry data.

\begin{tabular}{clclllclccc}
\hline FL\#1 & \multicolumn{2}{c}{ 60 Sek. } & \multicolumn{2}{c}{ 70. Sek. } & \multicolumn{2}{c}{ 80 Sek. } & \multicolumn{2}{c}{ 90 Sek. } & \multicolumn{2}{c}{ Random } \\
\hline 1 & LOGDA & 0 & LOGDA & 0 & SORIX & 0 & LIMVI & 0 & BIMPA & 72 \\
2 & LIMVI & 60 & NEPOX & 70 & BIMPA & 80 & SORIX & 90 & NEPOX & 159 \\
3 & AGAVA & 120 & LOGDA & 140 & BIMPA & 160 & SORIX & 180 & SORIX & 201 \\
4 & NEPOX & 180 & AGAVA & 210 & AGAVA & 240 & SORIX & 270 & SORIX & 265 \\
5 & AGAVA & 240 & SORIX & 280 & BIMPA & 320 & AGAVA & 360 & AGAVA & 357 \\
6 & SORIX & 300 & AGAVA & 350 & AGAVA & 400 & LIMVI & 450 & SORIX & 477 \\
7 & SORIX & 364 & AGAVA & 420 & SORIX & 480 & AGAVA & 540 & LIMVI & 561 \\
8 & LOGDA & 424 & LOGDA & 490 & AGAVA & 560 & LOGDA & 630 & LIMVI & 625 \\
9 & LIMVI & 484 & AGAVA & 560 & NEPOX & 640 & LOGDA & 720 & NEPOX & 671 \\
10 & LIMVI & 548 & LOGDA & 630 & LOGDA & 720 & AGAVA & 810 & NEPOX & 737 \\
\hline
\end{tabular}

Each of these samples was analyzed through the three scenarios, $3 \mathrm{~L}, 2 \mathrm{~L}$, and $1 \mathrm{~L}$, to assess the quality of the landing queue. For such calculations, reference was made to the determination of the nominal flight time of the aircraft. Nominal time means the time of flight of the aircraft in each scenario, calculated based on the length of the aircraft's route and assumed speeds at waypoints available on STAR charts.

\subsubsection{Scenario $1-3 \mathrm{~L}$}

The first scenario assumed the implementation of the full STAR procedure. Each arrival aircraft shall make a full flight from $w p_{\mathrm{i}}$ to $w p_{11}$. The aircraft arrived at individual entry gates and carried out the flight according to the scheme shown in Figure 5.

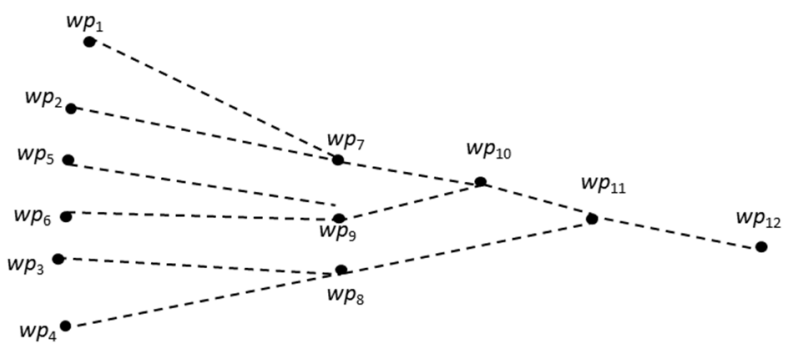

Figure 5. A scheme of aircraft in STAR procedure.

The results (time increase) in this simulation were conformed to the normal distribution and aligned with the parameters presented in Table 3.

Table 3. Parameters in Scenario 1.

\begin{tabular}{cccccc}
\hline Scenario & 3L_60 & 3L_70 & 3L_80 & 3L_90 & 3L_R \\
\hline Mean & 0.08554 & 0.06984 & 0.05297 & 0.04201 & 0.06042 \\
Standard & 0.038738 & 0.032175 & 0.030378 & 0.026763 & 0.035929 \\
deviation & & 0.084177 & 0.157901 & 0.129552 & 0.141807 \\
Statistic D & 0.064415 & 0.453352 & 0.012081 & 0.063582 & 0.032294 \\
Value p & 0.776507 & &
\end{tabular}

The shortest average time increase was obtained for the aircraft arriving at $90 \mathrm{~s}$ intervals and was $4.2 \%$. The longest increase in time was for the sample of arrivals every $60 \mathrm{~s}(8.5 \%)$ (Figure 6). 


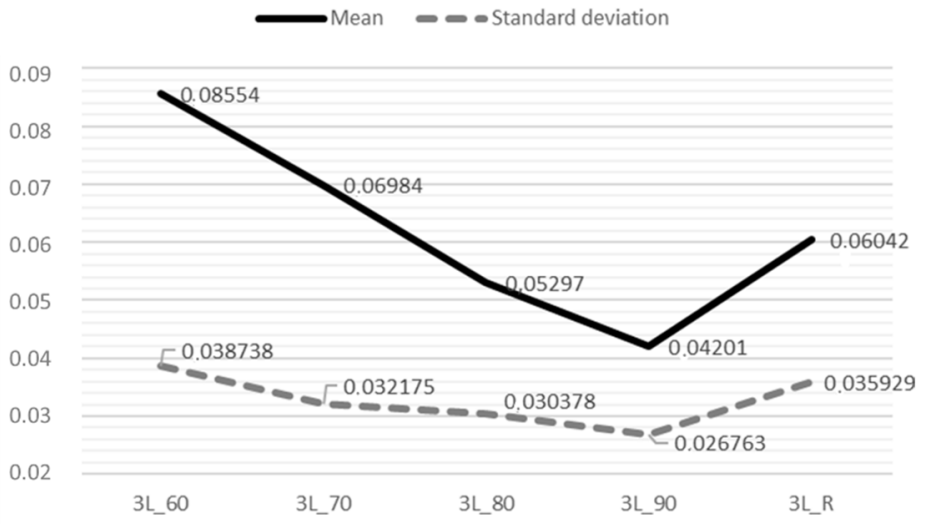

Figure 6. Mean increase time in each version of Scenario 1.

\subsubsection{Scenario $2-2 \mathrm{~L}$}

The second scenario assumed the flight of aircraft by combining the STAR procedure and shortcuts. It was assumed that the aircraft arrive at the entrance gate and initially fly along the designated trajectories in the STAR procedure. In the next phase, the flights take place after the given shortcuts to point $w p_{11}$. Table 4 presents the aircraft's flight routes.

Table 4. The aircraft's flight routes in Scenario 2.

\begin{tabular}{cc}
\hline Entry & Route \\
\hline NEPOX & XIMPU, NIMIS, REMDI, WA413 \\
LIMVI & WA442, EMKEN, TOSLU, XIMPU, NIMIS, \\
SORIX & REMDI, WA413 \\
BIMPA & OLDIM, WA413 \\
AGAVA & OLDIM, WA413 \\
LOGDA & BEMRA, WA413 \\
\end{tabular}

The aircraft performed the routes according to the diagram shown in Figure 7, which shows the two-step method of merging aircraft streams.

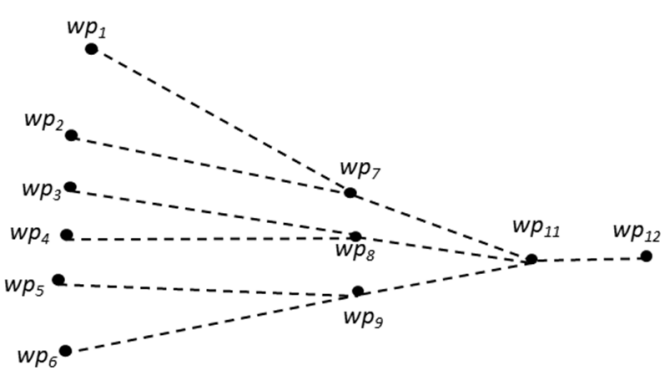

Figure 7. Scheme of merging aircraft in Scenario 2.

The aircraft performed the routes according to the diagram shown in Figure 7, in which the two-step method of merging aircraft streams was shown. The results (time increase) obtained in the second scenario also showed compliance with the normal distribution with the parameters presented in Table 5 . 
Table 5. Parameters in Scenario 2.

\begin{tabular}{cccccc}
\hline Scenario & 2L_60 & 2L_70 & 2L_80 & 2L_90 & 2L_R \\
\hline $\begin{array}{c}\text { Mean } \\
\text { Standard }\end{array}$ & 0.07877 & 0.06544 & 0.05981 & 0.04964 & 0.06095 \\
deviation & 0.049825 & 0.043084 & 0.04317 & 0.035022 & 0.040631 \\
$\begin{array}{c}\text { Statistic D } \\
\text { Value p }\end{array}$ & 0.129324 & 0.134815 & 0.142153 & 0.12743 & 0.158212 \\
\hline
\end{tabular}

As in Scenario 1, the shortest mean time increase was obtained for aircraft arrivals at intervals of $90 \mathrm{~s}$ and was $4.9 \%$. On the other hand, the longest increase in time concerned the sample concerning arrivals every $60 \mathrm{~s}(7.8 \%)$ (Figure 8 ). An increase in time can be seen compared to the results obtained in Scenario 1.

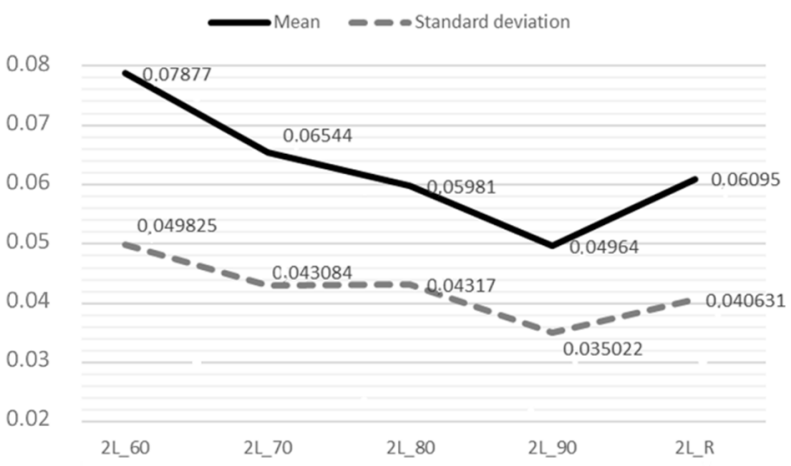

Figure 8. Mean increase time in each version of Scenario 2.

\subsubsection{Scenario $3-1 \mathrm{~L}$}

The second scenario assumed the flight of aircraft by combining the STAR procedure and shortcuts. It was assumed that the aircraft arrive at the entrance gate and initially fly along the designated trajectories. Scenario 3 concerned the simplified merging procedure of aircraft streams. Aircraft routes are followed by shortcuts. Aircraft arriving at TMA are directed directly to WA413. Only aircraft entering the TMA via the waypoint LIMVI are directed to the waypoint BEMRA and only directly to the waypoint WA413. Such a solution must be implemented due to the location of the airport in relation to the LIMVI point. In this scenario, the merging of aircraft streams takes place once. The scheme of the procedure is shown in Figure 9.

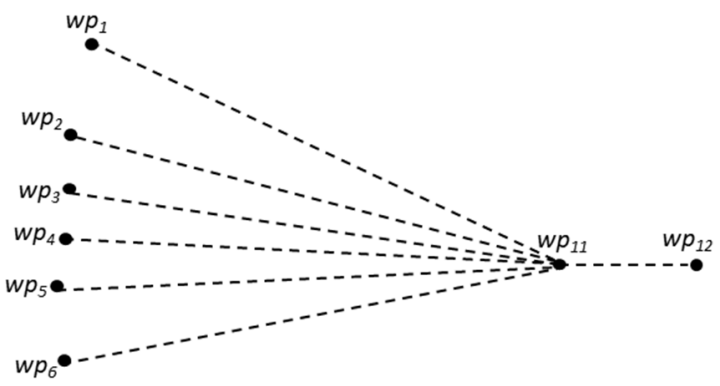

Figure 9. Scheme of merging aircraft in Scenario 3.

The sample was verified with the compliance results with the normal distribution with the parameters presented in Table 6. 
Table 6. Parameters in Scenario 3.

\begin{tabular}{cccccc}
\hline Scenario & 1L_60 & 1L_70 & 1L_80 & 1L_90 & 1L_R \\
\hline $\begin{array}{c}\text { Mean } \\
\text { Standard }\end{array}$ & 0.10349 & 0.08488 & 0.08682 & 0.06319 & 0.07478 \\
deviation & 0.059796 & 0.058525 & 0.059589 & 0.042685 & 0.046371 \\
$\begin{array}{c}\text { Statistic D } \\
\text { Value p }\end{array}$ & 0.116597 & 0.140014 & 0.146602 & 0.114544 & 0.152484 \\
\hline
\end{tabular}

In Scenario 3, the results showed that the shortest average time increase was obtained for arrivals of aircraft at intervals of $90 \mathrm{~s}$ and was $6.3 \%$. On the other hand, the longest increase in time concerned the sample concerning arrivals every $60 \mathrm{~s}(10.3 \%)$ (Figure 10). This scenario also shows a greater increase in time compared to the previous scenarios.

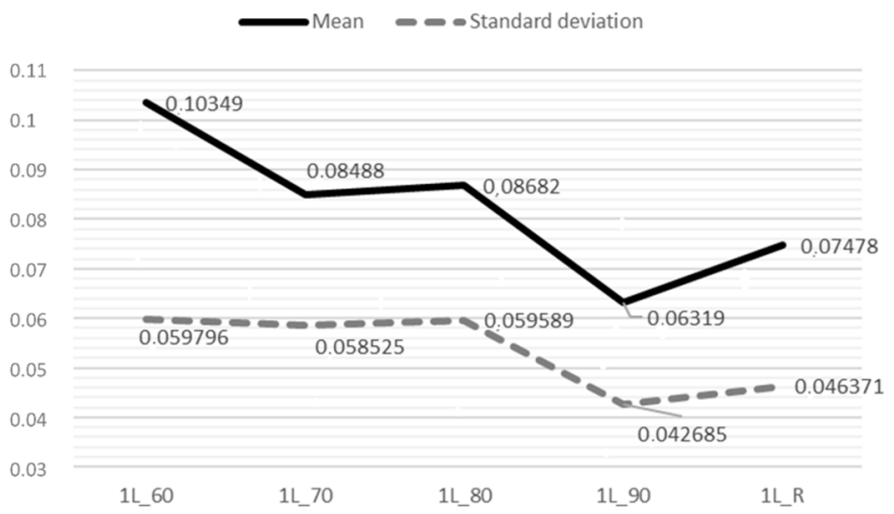

Figure 10. Mean increase time in each version of Scenario 3.

\subsection{Summary of the Results}

The conducted simulations made it possible to specify conclusions regarding the quality of the queue using the parameter of increasing the sequence execution time to the nominal time. Percentage increments are relative to a nominal time for each scenario. For example, in Scenario 3, with the most extensive use of shortcuts, the percentage increase is the largest $(8.3 \%)$, but this sequence's overall average execution time is only $12.26 \mathrm{~min}$. In terms of global fuel consumption, it is, therefore, the most advantageous option. Figure 11 presents the results for each scenario. The results obtained show that the best quality of the queue was obtained for the $1 \mathrm{~L}$ scenario, i.e., using routes with shortcuts.

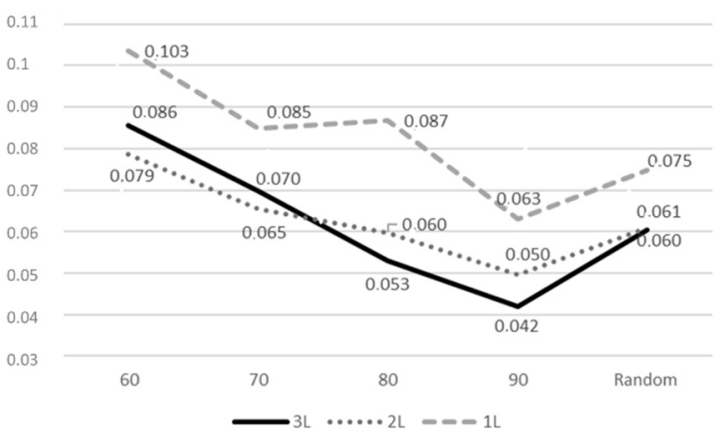

Figure 11. Mean increase time in each scenario.

The conducted research shows that aircraft arrival times to the TMA region are also an essential element. The results are summarized in Table 7. 
Table 7. Summary of the results of the simulation.

\begin{tabular}{cccc}
\hline Scenario & Scenario 1 & Scenario 2 & Scenario 3 \\
\hline Average time (min) & 20.35 & 14.7 & 12.26 \\
$\begin{array}{c}\text { Mean arrival increase } \\
\text { time (\%) }\end{array}$ & 6.2 & 6.3 & 8.3 \\
\hline
\end{tabular}

The simulation adopted assumed various methods of merging the streams of landing aircraft. The research started with the scenario in which the aircraft was moving along the routes of the STAR procedure. In this case, the aircraft streams were merged three times. In the second scenario, a two-step merging of aircraft streams was assumed. The third simulation concerned merging units, i.e., the implementation of arrival routes to the last straight after shortcuts. The obtained results indicate that the smallest average increases in time were obtained for the last scenario. Of course, it should be noted that simplified merging methods generally result in shorter execution times for landing sequences of aircraft. The obtained results are not obvious, as there may be situations of simultaneous or similar reporting of aircraft. Then, very long individual aircraft delays may occur. Interference can also cause delays.

\subsection{Fuel Consumptions Analysis}

Aviation is one of the important modes of transport that have a negative impact on the natural environment. The report of the European Environment Agency indicates measures to minimize air pollution, which can be implemented in the area of aircraft construction, as well as during the organization of air traffic [28]. The emission of aviation pollutants results from the combustion of fuel used for propulsion, and their level depends on the quality of the fuel and the combustion process. The greatest amount of pollutants into the environment are caused by passenger and transport aircraft propulsion units, which have the highest power and consume the most fuel, in proportion to the value of the generated thrust [29]. The main place where toxic compounds are generated are the upper layers, i.e., at altitudes of 8-12 km above sea level, where long-haul flights take place [30]. About $5-10 \%$ of world aviation fuel consumption occurs at altitudes not exceeding $1 \mathrm{~km}$ [31]. Air traffic planning can reduce or increase fuel consumption. In the paper [32], the authors presented a landing plane model that finds a schedule that minimizes noise impact, overall fuel consumption, and delays under wake vortex separation. The results obtained were compared with actual operations at a large European airport to assess the potential level of improvement. Research has shown an improvement of up to $4.5 \%$ in overall fuel consumption by just modifying the arrival sequence at Madrid-Barajas Airport. The authors of the article [33] analyzed the flight path in order to minimize the environmental impact of aircraft during landing approach, taking into account noise, fuel consumption, and other operational limitations. The conducted research led to the development of conclusions that the continuous descent approach can reduce noise emissions by $-4 \mathrm{~dB}$ and fuel consumption by $-20 \%$ to $-10 \%$.

The obtained results were used to calculate the increased fuel consumption in this paper. Fuel consumption of a Boeing aircraft, e.g., 737-800, was assumed, with an average of about 5 tons of fuel per $1000 \mathrm{~km}$. A larger Boeing, for example, a 767, which weighs 185 tons, will burn 8 tons per $1000 \mathrm{~km}$ in the first hour of the flight. Then, the amount of fuel burned decreases to approximately 5-6 tons. By indicating that the average delay increase is $8.3 \%$ for Scenario 3, the aircraft will burn over $600 \mathrm{~L}$ more fuel in the first hour of flight. Even considering the average value of fuel consumption, the aircraft will burn more than $400 \mathrm{~L}$. Such estimates are for a unit aircraft. Taking into account the air traffic during the day, it can be estimated that, due to poor organization of the queue of landing aircraft, fuel consumption may be higher by up to 100 tons.

Of course, fuel consumption cannot be considered one-to-one mapping with the total execution time of the landing sequence. However, both values are very closely related to each other. The presented analysis was intended to indicate that the way of traffic 
organization and control impacts fuel consumption. The estimation was made based on the obtained simulation results. To better reflect this relationship, it would be necessary to consider the additional fuel consumption associated with the maneuvers (e.g., turns) to implement the strategy of merging streams in the context of the need to maintain the required separations between aircraft. Additionally, fuel consumption is also influenced by the vertical characteristics of the descending process, which were not considered. A more detailed analysis in this area, considering the indicated factors, will be the subject of our further work.

\section{Conclusions}

The problem of organizing the traffic of landing aircraft is extremely important from a practical point of view. The analyzed issue in the paper is an essential supplement to the problem of aircraft sequencing. The main aim of the research is to find the relationship between the selection of merging streams of landing aircraft and the obtained quality of the received queue. The paper presents a model of air traffic in the area of the airport, developed by CPN Tools and implemented for the Chopin airport. The model was realized as a colored, hierarchical, and priority Petri net. The conducted research concerned three scenarios of merging streams of landing aircraft. In each simulation, the results of increasing the time of flight to the nominal time were obtained. This approach allowed the quality of the landing queue to be determined. The performed simulations contained input data consisting of a sequence of 10 aircraft and were performed 100 times. By implementing the current state of research, the authors obtained a fairly unequivocal relationship, indicating that the shortest increase in the meantime occurs for the flight using shortcuts. We got slightly longer times for two-step merging.

The difference between Scenarios 1 and 2 was insignificant and amounted to $0.1 \%$. Thus, we found that merging in Scenario 3 is the best line of landing aircraft. The simulations performed with the use of the Petri nets model and the obtained results can be used for calculations related to increased fuel consumption. When analyzing the results, however, it should be noted that further work is necessary for this area, particularly considering the disturbances. Such work will be carried out in the next stage of research.

Author Contributions: Conceptualization, A.K. and J.S.; methodology, A.K. and J.S.; validation, J.S.; formal analysis, A.K.; investigation, A.K.; resources, J.S.; data curation, J.S.; writing-original draft preparation, A.K.; writing-review and editing, J.S.; visualization, A.K.; supervision, J.S.; project administration, A.K.; funding acquisition, A.K. All authors have read and agreed to the published version of the manuscript.

Funding: This research received no external funding. APC was funded by Warsaw University of Technology within the the grant in the Scientific Discipline of Civil Engineering and Transport.

Institutional Review Board Statement: Not applicable.

Informed Consent Statement: Not applicable.

Data Availability Statement: The data presented in this study are available on request from the corresponding author.

Conflicts of Interest: The authors declare no conflict of interest. 


\section{References}

1. Kwasiborska, A.; Skorupski, J. Metody Szeregowania Zadań Jako Narzędzie Rozwiazywania Problemu Sekwencjonowania Samolotów; Prace Naukowe Politechniki Warszawskiej, Transport: Warszawa, Poland, 2014; Volume 101, pp. 55-62.

2. Bianco, L.; Nicoletti, B.; Ricciardelli, S. An algorithm for optimal sequencing of aircraft in the near terminal area. Lect. Notes Control Inf. Sci. 1978, 7, 443-453.

3. Dear, R.G.; Sherif, Y.S. An algorithm for computer assisted sequencing and scheduling of terminal area operations. Transp. Res. Part A Gen. 1991, 25, 129-139. [CrossRef]

4. Dell'Olmo, P.; Bianco, L.; Giordani, S. Models and Algorithms for Real-Time Control of Aircraft Landings; International Symposium on Operations Research; Springer: Berlin/Heidelberg, Germany, 1997; p. 125.

5. Huang, I.-S.; Chung, T.-H. Modelling and analysis of air traffic control systems using hierarchical timed coloured Petri nets. Trans. Inst. Meas. Control 2010, 33, 30-49. [CrossRef]

6. Kwasiborska, A.; Markiewicz, K. Metody Listowego Szeregowania Samolotów Lądujących Jako Narzędzie Wspomagania Kontrolera w Podejmowaniu Decyzji; Prace Naukowe Politechniki Warszawskiej, Transport: Warszawa, Poland, 2014; Volume 104.

7. Boursier, L.; Favennec, B.; Hoffman, E.; Trzmiel, A.; Vergne, F.; Zeghal, K. Merging Arrival Flows without Heading Instructions. In Proceedings of the 7th USA/Europe Air Traffic Management R\&D Seminar, Barcelona, Spain, 2-5 July 2007.

8. Soomer, M.J.; Franx, G.J. Scheduling aircraft landings using airlines' preferences. Eur. J. Oper. Res. 2008, 190, 277-291. [CrossRef]

9. Smedt, D.; Bronsvoort, J.; McDonald, G. Controlled Time of Arrival Feasibility Analysis. In Proceedings of the Tenth USA/Europe Air Traffic Management Research and Development Seminar (ATM2013), Chicago, IL, USA, 10-13 June 2013.

10. Balakrishnan, H.; Chandran, B. Scheduling Aircraft Landings under Constrained Position Shifting. In AIAA Guidance, Navigation, and Control Conference and Exhibit; American Institute of Aeronautics and Astronautics: Keystone, CO, USA, 2006 ; pp. 1-21.

11. Beasley, J.E.; Krishnamoorthy, M.; Sharaiha, Y.M.; Abramson, D. Scheduling aircraft landings-The static case. Transp. Sci. 2000, 34, 180-197. [CrossRef]

12. Beasley, J.E.; Sonander, J.; Havelock, P. Scheduling aircraft landings at London Heathrow using a population heuristic. J. Oper. Res. Soc. 2001, 52, 483-493. [CrossRef]

13. Berge, M.E.; Haraldsdottir, A.; Scharl, J.; Zhu, K.H. The generalized arrival planner (GARP): Modeling and analysis for arrival planning. In Proceedings of the 28th International Congress of the Aeronautical Sciences ICAS 2012, Brisbane, Australia, 23-28 September 2012.

14. Caprì, S.; Ignaccolo, M. Genetic algorithms for solving the aircraft-sequencing problem: The introduction of departures into the dynamic model. J. Air Transp. Manag. 2004, 10, 345-351. [CrossRef]

15. Brentnall, A.R. Aircraft Arrival Management. Ph.D. Dissertation, University of Southampton, Southampton, UK, 2006.

16. Hong, Y.; Choi, B.; Lee, S.; Lee, K.; Kim, Y. Optimal and Practical Aircraft Sequencing and Scheduling for Point Merge System. IFAC-PapersOnLine 2017, 50, 14644-14649. [CrossRef]

17. Kapolke, M.; Fürstenau, N.; Heidt, A.; Liers, F.; Mittendorf, M.; Weiß, C. Pre-tactical optimization of runway utilization under uncertainty. J. Air Transp. Manag. 2016, 56, 48-56. [CrossRef]

18. Corolli, L.; Lulli, G.; Ntaimo, L. The time slot allocation problem under uncertain capacity. Transp. Res. Part C Emerg. Technol. 2014, 46, 16-29. [CrossRef]

19. Jagieło, D.; Kwasiborska, A. The Concept of Tool to Support the Work of Air Traffic Controller in the Field of Aircraft Landing Scheduling in the TMA with Little Traffic, w: Smart Solutions in Today's Transport/Mikulski Jerzy (red.), Communications in Computer and Information Science. Springer International Publishing: Berlin/Heidelberg, Germany, 2017; Volume 715, pp. 436-446. ISBN 978-3-319-66250-3. [CrossRef]

20. Kwasiborska, A.; Skorupski, J. Analysis of the Process of Merging Air Traffic Streams. Case Study of TMA Warsaw. In Management Perspective for Transport Telematics/Mikulski Jerzy (red.), Communications in Computer and Information Science; Springer: Berlin/Heidelberg, Germany, 2018; pp. 320-334. ISBN 978-3-319-97955-7. [CrossRef]

21. Skorupski, J.; Florowski, A. Method for evaluating the landing aircraft sequence under disturbed conditions with the use of Petri nets. Aeronaut. J. 2016, 120, 819-844. [CrossRef]

22. Kovacs, A.; Nemeth, E.; Hangos, K.M. Modeling and optimization of runway traffic flow using coloured Petri nets. In Proceedings of the International Conference on Control and Automation, Budapest, Hungary, 26-29 June 2005; Volume 2, pp. 881-886.

23. Sadiq, A.; Ahmad, F.; Khan, S.A.; Valverde, J.C.; Naz, T.; Anwar, M.W. Modeling and analysis of departure routine in air traffic control based on Petri nets. Neural. Comput. Applic. 2014, 25, 1099-1109. [CrossRef]

24. Tang, X.M.; Wang, Y.T.; Han, S.C. Aircraft taxi route planning for A-SMGCS based on discrete event dynamic system modeling. In Proceedings of the ICCMS 2010 International Conference on Computer Modeling and Simulation, Sanya, China, 22-24 January 2010.

25. Vidosavljević, A.; Toŝić, V. Modeling of turnaround process using petri nets. In Proceedings of the 14th ATRS World Conference, Porto, Portugal, 6-9 July 2010.

26. Murata, T. Petri Nets: Properties, Analysis and Applications. Proc. IEEE 1989, 77, 541-580. [CrossRef]

27. Skorupski, J. Model of the hierarchical process of managing the approaching air traffic in the terminal area. Commun. Comput. Inf. Sci. 2015, 531, 108-120. [CrossRef]

28. EEA Report. Aviation and Shipping_Impacts on Europe's Environment TERM 2017: Transport and Environment Reporting Mechanism (TERM); Report, No 22/2017; European Economic Area: København, Denmark, 2017; ISSN 1977-8449. 
29. Kamiński, M.; Pospolita, W.; Cholewiński, M.; Łagocka, A. Emisja zanieczyszczeń z sektora transportu lotniczego i jej wpływ na zdrowie człowieka. Kosm. Probl. Nauk. Biol. 2016, 4, 487-493.

30. Stevenson, D.S.; Doherty, R.M.; Sanderson, M.G.; Collins, W.J.; Johnson, C.E.; Derwent, R.G. Radiative forcing from aircraft NOx emissions: Mechanism seasonal dependence. J. Geophys. Res. 2014, 109, D17307. [CrossRef]

31. Kim, B.Y.; Fleming, G.G.; Lee, J.J.; Waitz, I.A.; Clarke, J.-P.; Balasubramanian, S.; Malwitz, A.; Klima, K.; Locke, M.; Holsclaw, C.A.; et al. System for assessing Aviation's Global Emissions (SAGE). Part 1: Model description and inventory results. Transp. Res. D 2017, 12, 325-346. [CrossRef]

32. Rodríguez-Díaz, A.; Adenso-Díaz, B.; González-Torre, P.L. Improving aircraft approach operations taking into account noise and fuel consumption. J. Air Transp. Manag. 2019, 77, 46-56. [CrossRef]

33. Salah, K. Environmental impact reduction of commercial aircraft around airports. Less noise and less fuel consumption. Eur. Transp. Res. Rev. 2014, 6, 71-84. [CrossRef] 